\title{
Research on the New College English Teaching Model that Integrates Mobile Learning
}

\author{
Wenjuan Zhao \\ Xi’an International University, Shaanxi, Xi’an, China, 710077
}

\author{
Keywords: Mobile Learning; College English Teaching; Innovation of Teaching Model
}

\begin{abstract}
At present, mobile learning is a new trend of teaching model, this model based on mobile learning can break through the limitation of space and time in traditional classroom. Moreover, it is possible to form a new model of college English teaching by using multiple resources of the mobile Internet. Under the background of the deepening reform of higher education, mobile learning provides more profound teaching resources and more neoteric teaching ways for college English teaching, and it is more suitable for modern college students' ideology and behavior. However, since the development of mobile learning in our country has just started, there are still some shortcomings in the process of integration of traditional teaching with mobile learning. In this paper, the author will combine his own practical work experience and deliberate over the new model of college English teaching that integrates mobile learning.
\end{abstract}

As the rapid development of mobile Internet of China, all kinds of mobile smart devices have become the close friends of the college students, a lot of mobile items have become the necessities of the modern college students and occupied the irreplaceable role in the college student's life and their study, such as smart phone, panel computer, Wifi, and 4G. At the same time, mobile networks and mobile devices also play a significant role in various industries by virtue of their special functions. Mobile learning means that the learning behavior by the virtue of mobile network and mobile devices, from the teaching point of view, the teaching based on mobile learning can provide a more convenient teaching method for traditional teaching. It solves the limitation of time and space of the traditional classroom, and mobile learning can also provide abundant resources for teaching work by virtue of its Internet connection function; it can also realize the instant communication between teachers and students, and between students and students, so as to greatly improve the efficiency and quality of college English teaching. At present, the college English teaching model which integrates mobile learning has become a new teaching method, which provides a new way for the innovation of college English teaching.

\section{The necessity of integrating mobile learning into college English teaching}

College English is a compulsory course in Chinese higher education. However, from the actual teaching results, most students only study English for exams, and few students are really proficient in using English. The biggest reason is that the English learning of college students only stays in the classroom without further practices after class. Therefore, the necessity of integrating mobile learning in college English teaching is as below:

First, it can cultivate the students' independent learning consciousness. The personality of contemporary college students is distinctive, so, to cultivate students' independent learning consciousness is to cultivate their interest in learning. Mobile learning belongs to the non-conventional learning outside the classroom, it has high efficiency and convenience, and it can satisfy the students' pursuit of learning efficiency. By means of mobile learning, the contents of English learning can be divided into many small sections and that are refined. At the some time, the flexible terminal devices can also enhance students' interest in learning, so as to cultivate the students' independent learning consciousness and behavior.

Second, build a language circumstance. To master a second language, practice is the most important, but due to the hours of class, few students can really practice English. Mobile learning 
can solve this problem and help students build a better language circumstance. Mobile learning has great convenience, students can use mobile devices to practice English anytime and anywhere after class, this kind of exercise includes all the aspects such as listening, speaking, reading and writing, so as to create a better practice circumstance for the students.

\section{The feasibility of integrating mobile learning into college English teaching}

The conception of mobile learning has come into being and practiced for more than ten years, but the real development is that in the past two years, the feasibility of integrating it into college English teaching is as follows:

\subsection{Meeting the practical needs of college students}

Nowadays, mobile devices have become a kind of necessity for college students; they could solve all kind of problems in their daily life by mobile devices. They are fond of for online shopping, online booking, a lot of APPs are their favorites such as Meituan, Ctrip, and so on, so, the contemporary college students easily to use mobile devices for learning. At the same time, due to the limitation of textbooks and class hours, students can not learn English and practice English anytime and anywhere. But the mobile learning method can meet the practical needs of college students. In many colleges and universities, we can easily see that there are many students who use mobile phones and panel computers to look up words, we can see that students who practice English listening by MP3 players and other mobile phones. The students whose majors are English also use mobile devices to watch English movies, TV series, and so on; these show that mobile devices meet the real needs of college students to learn English.

\subsection{Hardware of mobile device is more advanced and cheaper.}

As the constant development of science and technology, the technology of mobile smart devices in China has been maturing. In the case of smart phones, the price of most the smart phone in the market of our country is concentrated in the range of 500 to 10000 Yuan, and it can meet the needs of people with different consumption capacity. As the fastest receptive and trendy social group, college students can not leave a mobile device any more. The investigation shows that the percentage of college students holding smart phone is $99.9 \%$, which is the basic hardware condition to realize mobile learning.

In terms of cost, mobile devices need network support to realize the Internet connection. The current wireless network technology and 4G technology are very mature, which provides important technical support for the implementation of mobile learning. With the efforts of the three major domestic telecom operators, the cost of data has been continuously cheaper and cheaper, which has greatly reduced the cost of Internet access for college students. Some colleges and universities have even realized free wireless network coverage, which provides a guarantee for mobile learning.

\subsection{Abundant learning resources for mobile learning}

As the rapid development of mobile devices and the deepening of the concept of mobile learning, some software companies in China began or completed the development of mobile learning software. Many mobile learning enthusiasts also developed a lot of mobile learning related operations, and these achievements are feasible for IOS, Android and so on. In terms of resources, many English learning databases, websites and platforms have been set up, including not only document resources, but also audio-visual resources and case resources, which have contributed to the development of mobile learning of college English.

\section{Application of mobile learning mode in college English teaching}

As a new teaching model, the application of mobile learning will undoubtedly have a certain impact on the traditional teaching model. Therefore, how to integrate mobile teaching into traditional teaching and ensure to take the best use of it to college English teaching has become an 
important issue. In this charter, the author will combine his own practical experience and thinking, and then summarize the application strategies of integrating mobile learning into college English teaching.

\subsection{Teachers should play a leading role from macroscopic aspect}

Mobile devices can not only for learning, but also for entertaining. Among the current college students, the college students who indulge in mobile devices and Internet are common. Therefore, teachers should play their own macro-guiding role in the process of integrating college English teaching and mobile learning, so as to let the students understand mobile learning correctly and use mobile devices correctly.

In the relevant investigation, many students understand mobile learning as "playing with mobile phones" and do not have a correct understanding of the connotation of mobile learning. Therefore, this requires active guidance from teachers. To help students understand the correct English mobile learning, teachers can make mobile learning plans for students, such as translating English articles via mobile devices, finding English writing materials through mobile devices, and so on. In fact, at present, some college students in our country are unable to study independently, especially for abstract English learning, which is more boring for them. by this kind of guidance from teachers, It can not only help students to use mobile devices to learn correctly, but also help students to form the habit of correct independent learning, so as to promote the quality of their English teaching.

\subsection{Active interaction and communication}

Mobile devices can break through space constraints and achieve interaction and communication between teachers and students. This kind of interaction and communication can increase the feelings between teachers and students, enhance the learning atmosphere, and enhance students' subjective initiative in learning.

After the completion of the class teaching, teachers can use mobile devices to communicate with the students by creating QQ groups, WeChat groups, and campus online stations etc. In the process of interaction after class, the teachers should pay attention to their own attitudes; they should change the stern image of the class and become the friends of the students. At the same time, English recitation, English essay writing, early morning English word recitation and other forms can be organized to interact with the students. For example, teachers can select familiar or preferred paragraphs of English articles, and then ask the students to recite English respectively via WeChat group or QQ groups, , and finally select the best students. Teachers' behavior of setting an example can improve students' motivation to participate, and the method of competition can arouse students' interest, so as to create a relaxed and enthusiastic learning atmosphere that is quite different from the atmosphere in classroom.

This kind of interaction and communication can also make a more comprehensive evaluation of the students. The after class approach has changed the formal and rigorous atmosphere in the classroom, so teachers can discover the strengths and weaknesses of each student in English learning from different angles. By recording and analysis, they can make a more comprehensive evaluation of the students, and adopt different methods in combination with the results of the evaluation, and finally improve the students' English proficiency and ability synthetically.

\subsection{Helping the students to actively communicate with the outside world}

The biggest difficulty in learning a second language is the mental handicap of the learners themselves. Many college students think that their English has a strong "Chinese flavor" both in writing and speaking, so they have been afraid to speak out loudly and writing confidently, this is an important problem restricting the improvement of college students' English ability. The Internet has a strong openness and integration, so teachers can help the students to make positive contact with the outside world, so that the students can improve their English proficiency in the mobile network environment.

Teachers can help colleges students to collect and organize relevant English online forums, English research websites, various English resource platforms, etc. Social English enthusiasts and 
even teachers and professors in the website can exchange their opinions and confrontation by means of taking part in oral English contest, English composition contest and so on. The teachers should let the students find the merits and shortcomings of themselves in the environment of the Internet, and then challenge themselves, prove themselves. It not only can enrich the way for the students' learn, but also can give students a platform to show their own. At the some time, it can let the students feel the "Crouching Tiger, Hidden Dragon" in the Internet environment, so the students can observe the fresh environment and understand the different charm of English, grasp the different methods of learning English, so as to improve their English ability.

\section{Summary}

Mobile learning is the product of the modern Internet era. As the constant development and progress of network technology in China, the hardware devices for mobile learning are more advanced, and more extensive learning resources, mobile learning is more suitable for the learning needs and behavior of modern college students. English itself is an open language. Integrating mobile learning into college English teaching not only meets the requirements of higher education reform, but also meets the development trend of college English teaching. This requires the educators to constantly sum up and think about the application of mobile learning in college English teaching, to promote the scientific integration of mobile learning and college English teaching, and to take the best of its greatest value.

\section{References}

[1] Li Nanli, Sheng Cong. Summary of Research on Mobile Learning in China 2006-2011[J]. Adult Education, 2012(18).

[2] Ye Jin. Comparative Study on the Teaching Reform of College English E-teaching[J]. Research and Exploration in Laboratory, 2011, 30(8).

[3] Zhang Yihang. The Influence of Independent Multimedia Network Learning on College English Teaching Model [J]. China Economist, 2011(1).

[4] Zhao Guilin. On network individualized Learning of College English Listening [J]. Research and Exploration in Laboratory, 2009, 28(6).

[5] Zhao Haidong. On Transformation of Modern teaching methods based on Information Technology [J]. China Educational Technology \& Equipment, 2014(11).

[6] Wang Zhihong. Briefly Discussion on the Construction and Management of Computer Informatization[J]. Network Security Technology and Application, 2015. 